\title{
MEDIFAM. Órgano de difusión de la Sociedad Española de Medicina de Familia y Comunitaria
}

partir de este primer número del volumen número once de MEDIFAM, justo en el comienzo del decimoprimer año desde su primera edición, nuestra revista se convierte en el Órgano de Difusión de la semFYC.

Han sido muchos los lectores y autores, y muchos de nuestros colaboradores y de los miembros del Comité de Expertos, los que nos solicitaban desde hace años el establecimiento de fórmulas de participación y colaboración con nuestra Sociedad Científica. Desde que iniciamos este proyecto, hace más de diez años, ha sido intención permanente de todos los que trabajamos en MEDIFAM, pero especialmente de la Dirección y Consejo Editorial, el lograr un acuerdo de colaboración y participación con la semFYC, por entender que MEDIFAM representaba y defendía íntegramente los intereses, la línea científica y el desarrollo de la práctica de calidad de la Medicina de Familia, y que el apoyo y aval de la semFYC podía suponer un refrendo significativo de cara a los lectores y autores de trabajos de investigación de calidad.

Evidentemente, a tenor del tiempo transcurrido, ha sido una negociación difícil en la que la Sociedad MEDIFAM ha pretendido no perder su autonomía y mantener los objetivos científicos que dieron lugar a la publicación de la revista, y la semFYC ha buscado en todo momento el tener la suficiente seguridad como para poder avalar con garantías, mediante su apoyo y participación, una publicación que realmente pudiese representarla en todos sus aspectos y que pudiese sentir como suya.

Para ello se ha conseguido un modelo de participación equitativo en los órganos de gestión y administración en el que ambas partes están representadas por igual. Estos órganos de gestión son los que, a partir de ahora, definirán los objetivos, la línea editorial y la filosofía de la publicación, establecerán los mecanismos de evaluación y control y nombrarán al Director y Consejo Editorial de MEDIFAM, entre otras funciones.

Hasta el momento, MEDIFAM ha seguido una línea editorial y ha defendido una filosofía de la Medicina Familiar totalmente acorde, y sin que existiera ningún acuerdo previo, con la filosofía de la semFYC, por lo que es de esperar que no se requieran grandes cambios, al menos ideológicos y de objetivos, en el modelo de publicación existente hasta ahora.

Los principales objetivos de MEDIFAM, que se han mantenido desde su fundación, van a seguir estando presentes, de forma que nuestra revista pueda seguir siendo un instrumento útil y eficaz para la Medicina de Familia. Seguirán primando los objetivos docentes y el favorecer al máximo la investigación y la formación metodológica. Se mantendrán, con las mejoras que a partir de ahora se requieran, los sistemas de selección de artículos, los sistemas de control y los grupos de trabajo específicos que han 
hecho de MEDIFAM una publicación de calidad. Los contenidos seguirán siendo siempre los que más interesan al Médico de Familia y al desarrollo de nuestra especialidad. Seguiremos resaltando la investigación de calidad en los artículos de investigación Originales, la excelente práctica clínica que se desarrolla en el contexto de nuestra especialidad con las mejores aportaciones en forma de Notas Clínicas y Series de Casos, la colaboración con otros niveles asistenciales a través de la sección En colaboración con..... y la actualización en conocimientos, habilidades y destrezas mediantes secciones como Dinámica Familiar, Técnicas y Procedimientos en Medicina de Familia o Revisión Crítica de la Práctica Clínica. Las secciones de Editorial y Hablemos de....., secciones donde hemos buscado siempre la más autorizada opinión de expertos en aquellos temas sobre los que considerábamos que era necesario reflexionar o que más podían importar al médico de familia, serán a partir de ahora un magnífico foro para la expresión de la semFYC.

Si por algo se ha caracterizado MEDIFAM ha sido por su riguroso proceso de garantía de calidad. Esperamos mantener el mismo nivel en el proceso de selección de artículos, en la evaluación de revisores y expertos, en el quehacer de las comisiones de trabajo y en el control del proceso editorial. El lector tiene que seguir valorando los contenidos de MEDIFAM y el autor tiene que seguir confiando en una revista que mantiene un riguroso y serio proceso de selección.

Otra de las novedades y a la vez reto que se produce como consecuencia de este acuerdo es el que la revista MEDIFAM, como Órgano de difusión de la semFYC, tendrá desde ahora la obligación y la responsabilidad de publicar todas las comunicaciones y documentos institucionales de carácter científico de la Sociedad. Esta colaboración sin duda representará un aumento significativo de los contenidos científicos y muy probablemente nos obligará al aumento de la periodicidad en un futuro próximo.

También queremos destacar que, como consecuencia de este acuerdo de colaboración, y para que todos los socios de la semFYC reciban gratuitamente la publicación, nuestra tirada se incrementa de forma muy significativa, convirtiendose en una de las publicaciones con mayor tirada a nivel nacional.

Iniciamos otra nueva etapa en la que no van a prevalecer intereses de nadie en concreto ni de ningún grupo en particular. En MEDIFAM, ahora en estrecha colaboración con semFYC, vamos a seguir trabajando por una especialidad con una manera propia de sentir y realizar su práctica, defendiendo los intereses científicos de todos los médicos de familia, y contribuyendo, en la medida de nuestras posibilidades, al logro de una excelente Atención Primaria de Salud.

JOAQUÍN MORERA MONTES Director de MEDIFAM 